\title{
Student Opinions on Task-Based Approach as Formative Evaluation versus Exam-Based Approach as Summative Evaluation in Education
}

\section{Levent UZUN*}

\begin{abstract}
The present study investigated ELT students' opinions about the convenience of exam-based or task-based approaches for their learning process, concerning three criteria that relate to the effectiveness of task-based and exambased education: 1 . the contribution to the professional and personal development of the students (whether task-based or exam-based applications develop them better); 2. the contribution to their critical and creative skills; and 3. the advantages and disadvantages of task-based and exam-based approaches. Exam-based approach as summative assessment type and task-based approach as formative assessment type were compared in terms of their advantages and disadvantages. Findings indicate that the majority of the students are not satisfied with the summative assessment system. Participants believe that the formative evaluation approach is more appropriate for them. The results propose that the conventional approach, which is based on an exam-focused system in the English Language Teaching Department, should be changed in order to enhance future English teachers' creative skills as well as their personal and professional development as far as possible.
\end{abstract}

Keywords: Task-based approach, exam-based approach, formative assessment, summative assessment, ELT, education.

\footnotetext{
* Orcid ID: https://orcid.org/0000-0002-2321-391X, Assoc. Prof. Dr., Uludağ University, English Language Teaching, Turkey, ulevent@uludag.edu.tr

** Orcid ID: https://orcid.org/0000-0001-6281-5211, Turkey, sevvos@windowslive.com
} 


\section{INTRODUCTION}

Training students to become autonomous, reflective and critical thinkers by using the most appropriate and effective approach is one of the most crucial tasks of educators. Therefore, for example, educating a student in the English Language Teaching (ELT) Department effectively means, in a way, providing good and effective English education to rising generations.

Considering the weaknesses in teaching English as a foreign language (EFL) in Turkey due largely to the insufficiencies in the ELT programs in higher education (Öztürk \& Aydın, 2019; Erarslan, 2018; Uzun, 2016), it is possible to say that revisions need to be done in our ELT program (both in the content and how the content is delivered), because the problem, indeed, does not derive from the students only; it derives from the teachers also who have received training from non-influential educators who used ineffective approaches and methodologies, and inappropriate course contents, techniques, and materials. Arguably, changing and/or modifying these accordingly should be considered in order to receive the best results not only specifically in language education but also in education in general as much as possible.

In the present study, two very significant topics are spotlighted. The exam-based approach that is used predominantly in Turkey both in primary and higher education (Uztosun, 2013; Kilimci, 2009) in contrast to the task-based approach, as well as the appropriateness of summative versus formative evaluation and assessment approaches will be analysed to conclude which of these develop students' professional and personal lives more effectively. As there is no consensus in the literature related to summative and formative assessment and/or evaluation, the definitions of the mentioned concepts and how they will be regarded within the focus of the present research that concentrates on the exam-driven and task-based domains are stated in the following to clarify the stance of the researchers. Basically, the exam-based approach is considered as being summative assessment type and task-based approach is regarded as formative evaluation.

The exam-based approach is commonly used in almost all of the universities in Turkey. The exam-based approach in education can be basically defined as the system that primarily uses examinations and tests, usually at the end of certain periods, to evaluate and assess the quality and success of the students, which will be regarded as summative evaluation in the scope of the present study (Garrison \& Ehringhaus, 2007; Taras, 2008). This approach usually ignores or neglects personal inclinations, pertinence, future plans and conditions, etc. The exam-based approach, for different reasons, will usually lead to memorisation, surface learning, and an overall education that is mostly oriented towards passing exams rather than towards deep learning or intellectual improvement and wellbeing as is in project-based, problem-based, or task-based learning approaches (Lovett, 2013; Taras, 2005; Lau, 2016). However, universities particularly should be the environments where students improve their critical and reflective thinking to become 
autonomous and conscious individuals who will contribute and add value to the society by producing.

On the other hand, the task-based approach, which will be regarded as a formative evaluation system in the scope of the present study and that is adopted individually by some professors on their own initiative and adapted to their courses, enables students to do weekly tasks that can be diversified according to the personal features, needs and interests of the learners, and which will lead to an education that encourages responsibility-taking, planning of the process, learning by doing and creativity, etc. (Taras, 2008; Dixson \& Worrell, 2016). Almost everyone would agree that meaningful and well-planned tasks prepare people for life, as put forward in the following quote by Abigail Van Buren: "If you want children to keep their feet on the ground, put some responsibility on their shoulders." (http://thinkexist.com). Could we postulate the same for exams and tests?

Besides the educational systems, regardless of the field and approach in use, one of the most important subjects to be considered is assessment. Depending on what the education focuses on, the results instantly change. Therefore, it is possible to propose that the focus determines the learning outcomes (Lovett, 2013; McDowell, 1995; Jensen et. al, 2014; Teodorczuk et. al, 2018). In order to determine the most effective approach for ELT students, in the present study; the exam-based approach that leads to summative, and task-based approach that creates formative assessment types will be investigated, as well as correlations made between the two evaluation types in education.

The predetermined supposition of the researchers is that if the focus is on exams or tests, the education and evaluation will lean towards summative assessment. In summative assessment systems, a special focus on tests or exams is formed, and thus, special concentration is devoted to passing these, which becomes the ultimate and most important aim. Students usually skip the process of acquiring knowledge and skills by thinking ahead towards the date of the exams or tests, and study intensively during the exams or the week preceding the exams with the purpose of passing these with the highest grade possible, without obtaining knowledge or skills for long-term memory and use. It is indeed very hard to assess the special skills such as creativity, productivity, and critical thinking, especially with exams and tests. It would be very hard to deny the fact that in exam focused environment the information that students receive and use is kept in their short-term memory, just to save the day. Therefore, when the exams are over students feel fresh and ready to move on to a brand-new beginning simply by looking ahead for new information to consume or memorise, because new exams require new information. According to the observations and experiences of the researchers, the information that students were responsible for in the past exams becomes old, used up, and consumed.

Furthermore, sometimes students never see their exam or test papers and never receive detailed feedback on each test item or exam question or on their general performances 
in the exams, except the marks that are announced. This suggests that exams and tests have nothing much to offer learners except numerical evaluation results. There is hardly any feedback or scaffolding activity except the final grade. Additionally, sometimes it is hard for students to recall what they did or wrote in the exam, and so, they cannot know which exact parts were wrong or correct or to what extent. So, after-exam achievement is usually ignored or left incomplete. What is more, the presence of exams makes students anxious and stressful as they are unnecessarily attributed too much importance and are the vital criteria for passing or failing and indicators of academic success. Almost in every study in the literature it is reported that exams are harmful for the psychological and physical wellbeing of the students. Prabu (2015) reported that students very often highlight experiencing stress at predictable times each semester with the greatest sources of stress resulting from taking exams and grade competition. Sometimes students make mistakes just because of problems related to anxiety and stress.

On the other hand, again the predetermined supposition of the researchers is that if the focus is on the process, learning-by-doing, and acquisition and instalment of knowledge and skills in long-term memory, the education and evaluation will lean towards formative assessment (Santamaria Lancho et. al, 2018; Cantillon et al., 2017; Dixson \& Worrell, 2016; Lopez-Pastor \& Sicilia-Camacho, 2017). The aim will not necessarily be the exams or tests but the process itself. In this approach students will be encouraged to focus on what they are doing, and on improving their wellbeing by enriching their individual personal and academic worlds by the help of the education that they receive. Concentrating on the process will be easier by the help of meaningful and useful tasks, which are important alternatives to exams and tests, and thus, should be regarded seriously and used more often in education. Unlike exams and tests, tasks require learners to use both past and present knowledge as well as to involve individual skills while completing them. Tasks do not put students under pressure as much as exams do, because they are not irremediable like exams. Tasks are frequently given to students, and also extend beyond the class hours, which allow them to take their time to think critically and create something original, unlike exams, which are given in the classroom and require students to reply to some questions in a predetermined way without much time allowed to criticise and create. The function of the tasks is not to punish or reward students by urging them to fail or letting them pass, but to provide opportunities to use all of their existing knowledge and skills. At the end of each task, students come up with a product that will receive direct feedback from the teacher or fellow-students or both. As learners will not focus on just one point as they do in exams or ultimate assessment, in order to fully complete the given tasks, they need to have a full understanding of the idea of the lesson and what they want to achieve at the end of the semester or year. Also, this is a process that enables students to check their tasks again and again, correct them and also save them in a portfolio that can be accessed whenever wanted.

In short, it is not possible to object to or reject the vital role of the evaluation system in education that should be effective and appropriate, as it is one of the fundamental 
factors that learners, teachers, and authorities are associated with. The rationale of the current research is rather pragmatic than empirical. Therefore, studying exam-based and task-based approaches with relation to summative and formative evaluation should be seen as a very valid and essential endeavour. Additionally, there is significant amount of evidence in the literature claiming that exam-driven education is not only harmful for the mental and indirectly physical health of the students but also do not contribute much to the educational ideals and deep learning (Rillero \& Padgett, 2012; Yu \& Suen, 2005; Mackatiani, 2017; Kılıçkaya, 2016).

Therefore, all of the above stated reality and information becomes the absolute practicebased justification for the present study, which also underlines the necessity of reevaluating the current practices in education. Additionally, the present study will contribute to the field of ELT by revealing fresh data coming directly from the ELT teacher trainees as the heart of the matter.

\section{Literature Review}

\section{Summative and Formative Assessments}

Summative assessment considers evaluation as a product and evaluates students' achievements usually through exams and tests. On the other hand, formative assessment considers it as a process and improves students' learning through tasks and activities. Therefore, it is possible to conclude that formative assessment is a qualitative approach whereas the summative approach is quantitative. Alvarez, Ananda, Walqui, Sato and Rabinowitz (2014) stated that formative assessment improves evidence of learning through a range of tasks, changes the roles of students and teachers, uses learning advancement to achieve learning goals and monitor learning ends through meaningful feedback and adaptations in order to enhance directives for students, and enables them to become autonomous learners. Also, Hadi (2013) suggested that according to the results of their research, students are attracted to using TBLT (Task-Based Language Teaching), primarily because they believe that task-based learning improves learners' communication abilities.

Considering the evidence that naturally and essentially formative assessment enhances students' creative thinking and productive skills more than summative assessment, it might be quite an assertive proposition that education and learning, with regard to fulfilment of the potentials of the students, will benefit more from formative rather than summative evaluation. Accordingly, Uzun (2014) advocated that even though it seems that positivistic philosophies and quantitative approaches are more powerful in producing concrete benefit, there has been an increasing tendency to shift towards naturalistic and qualitative approaches. Furthermore, Uzun (2016) suggested that if the courses' content and the method were reviewed and reconstructed in a way that was less memorization-based but more permanent and by which interiorized information would be generated, it would be advantageous. In the same way, Yavuz and Topkaya (2013) also mentioned, in their study, one of Hismanoglu's (2012) studies that revealed the opinions of pre-service teachers about the general aspects of the program and 
course lecturers' teaching techniques, evaluation and assessment procedures. It was detected that the program met the pre-service teachers' expectations and needs substantially, but that it failed to indoctrinate their higher thinking skills such as creative thinking, critical thinking, and problem solving. From a different point of view, formative assessment is significant in ESL/EFL (English as a Second Language/ English as a Foreign Language) teaching and learning, as in the study of Cheng et. al, (2004), in which it is stated that every model of the teaching-learning process requires that teachers base their decisions-instructions, grading, and reporting on some knowledge of students' attainment of and progress towards desired learning outcomes in the process of education. Furthermore, Baranovskaya and Shaforostova (2017) argued that selfassessment plays a major role in ELT and explored the assessment activities which they embedded in the curriculum to develop self-assessment. According to the results, it can be inferred that formative assessment evaluates students in a process that includes the course with all possible factors, and thus, it can stimulate self-assessment better than summative assessment that mostly concentrates on the ultimate exams and/or tests. In addition, Shi (2017) analysed 2 groups of students, to whom were applied 2 different teaching styles, which used summative and formative assessment throughout a semester with the purpose of learning vocabulary. The results indicated that autonomy and interest in vocabulary learning increased in the group to which formative assessment was applied. Students became active in participating in classroom debates and collaboration, and started to make study plans and set goals autonomously. Also, they achieved consciousness and awareness of vocabulary learning autonomy. Positive opinions were held about formative assessment in vocabulary teaching by the students. Students' autonomy, attention, and confidence in English vocabulary learning were motivated by formative assessment. Therefore, it can be deduced that formative assessment can be applied in any course that requires any skill or area to have a good result, because according to the results it is clear that it helps students to become more creative, self-confident, cooperative, responsible, and, most importantly, autonomous.

Nevertheless, despite the fact that summative assessment aims only at the achievement of the students and focuses on the product instead of the process, which usually results in limited critical and creative thinking, when the situation around the world is considered, it can be seen that even though there are certain courses which employ the formative-qualitative approach, the courses which employ the summative-quantitative approach are in the majority. Examples of summative assessment include final projects, midterm and final exams, tests, etc. which usually create stress for students. This is despite awareness of the reality that summative evaluation mostly enhances decisionmaking among the given choices rather than encouraging students to create their own ideas and brand-new movements. Mohamadi, Alishahi and Soleimani (2014) asserted that exam apprehension could be one of many factors that have a potential influence on the exam score. Similarly, Alderson (2005) correlated summative assessment with long, conventional exams that were very stress-filled for students. Thus, instead of basing educational assessment merely on a final exam or tests at certain intervals, using 
continual evaluations such as portfolio, daily and/or weekly tasks, or dynamic evaluation seems more appropriate and useful for the students.

In view of the above, formative assessment improves students in many positive ways when it is compared with summative assessment. If something is done just for the sake of getting a good grade or being praised, permanence cannot be ensured and all the good things that have been done until that time can disappear; this is a situation that represents summative assessment and accordingly, an exam-based approach. On the other hand, if one does something for his/her own learning, that person becomes more aware of himself/herself and what he/she is doing, and knows his/her responsibilities, mistakes and limitations; this is a condition that represents formative assessment and accordingly, a task-based approach.

Uzun (2012) stated that even though many different techniques and methods have been suggested over the years, students have been regarded according to specific proficiency levels. This approach to students can be clearly seen in the exam-based approach which determines students' success by looking at the grades attained from tests, without considering other elements such as creative and critical thinking skills, being social, well-being, mood and ability of adaptation, being laid-back, technology disposition, etc., all of which are skills or characteristics that are very important for specific positions and/or jobs.

The most important question to ask, then, is; should formative assessment replace summative assessment in education? Or, why is formative assessment avoided? The answer was given by Ketabi and Ketabi (2014) as follows; despite the significance of formative assessment in ESL/EFL teaching and learning, the complexities and difficulties teachers confront in implementing formative assessment in their classes, the deficiency of studies in this area as well as the problems of making classroom evaluation as formative as possible and proposing ways to enhance classroom assessment that teachers should also focus become major and insoluble concerns. Notwithstanding the fact that formative assessment is not as easy to apply as summative assessment is, based on their research findings, Antoniou and James (2014) revealed that teachers had positive perceptions towards formative assessment and reported that it is an essential factor that can promote effective teaching and learning.

Consequently, Robert Stake (Miller at al., 2016) stated that formative assessment is like 'When the cook tastes the soup', whereas summative assessment is like 'When the customer tastes the soup'. Actually, this quotation clearly explains the main core idea of these concepts.

Can the task-based approach and formative evaluation develop students professionally and personally better than the exam-based and summative evaluation? According to the data and cases indicated so far, the answer seems to be positive. Many of the courses in the ELT Department of Uludag University, that is the location of the present research, are based on presentations and lecturing, and the assessments are mostly based on exams and presentations of the students. If the courses that adopt the exam-based 
approach were replaced with those that adopt the task-based approach, would students benefit more and improve better? It is like skiing; if you practice often, you learn how to balance. On the contrary, if you do not know how to ski but you just practice before you go skiing, maybe you can balance for a moment, but that does not mean that you have learned skiing and will be able to ski.

To sum up, in order to have qualified teachers in the future, there is a need first to have qualified teacher candidate students who do not necessarily memorise information before the exams but practice to use the information that is learnt. The methods and approaches that are used to deliver information and assess achievement should be considered carefully as the key elements of development in the area of professional and personal achievements which can change the operation of the system in a positive way and comply with the educational philosophies of the era.

The present study aimed at revealing ELT students' opinions about the convenience of exam-based and task-based approaches for their learning process; how they feel when confronted with exams, and whether the participants prefer exams or regular tasks more. The researchers also tried to catch hints related to how exams contribute to the creative thinking abilities of the participants, their short and/or long-term memories as well as professional and personal lives. The research questions were as follows:

1. What do the university students think about the exam-based versus task-based education?

2. Which assessment type is preferred more by the students; summative or formative?

3. What are the students' opinions about the benefits and disadvantages of task-based and exam-based approaches?

4. Which approach according to the students is more effective in developing them personally and professionally and improving critical and creative skills?

\section{METHOD}

The present study utilized both qualitative and quantitative methods in the procedure of research and data collection to ensure triangulation and in-depth investigation of the subject matter.

\section{Participants}

The participants were 50 students (29 female and 21 male) in the ELT department at the Faculty of Education in Bursa Uludag University. They attended their first (5 students), second (22 students), third (9 students) and fourth (14 students) years in the department during the study. The mother tongue of all participants was Turkish, and they have been learning English as a foreign language for over ten years. The number of the male participants was lower than that of the female participants in all grades (1st, 2nd, 3rd and 4th). The participants were randomly selected from among the volunteers 
who were contacted by posting a Google Form on WhatsApp groups. Table 1 presents the number and gender of the participants in each year.

Table 1.

Number and gender of participants according to grade

\begin{tabular}{|c|c|c|c|c|c|c|c|c|}
\hline Grade & \multicolumn{2}{|c|}{ 1st year } & \multicolumn{2}{|c|}{ 2nd year } & \multicolumn{2}{|c|}{ 3rd year } & \multicolumn{2}{|c|}{ 4th year } \\
\hline Gender & $\mathrm{F}$ & $\mathrm{M}$ & $\mathrm{F}$ & $\mathrm{M}$ & $\mathrm{F}$ & $\mathrm{M}$ & $\mathrm{F}$ & $\mathrm{M}$ \\
\hline Number $(\mathrm{N})$ & 3 & 2 & 12 & 10 & 6 & 3 & 8 & 6 \\
\hline Total & \multicolumn{2}{|c|}{5} & \multicolumn{2}{|c|}{22} & \multicolumn{2}{|c|}{9} & \multicolumn{2}{|c|}{14} \\
\hline
\end{tabular}

\section{Instruments}

The data were collected through two data collection tools: a survey was applied for the quantitative part of the study, and an interview was applied for the qualitative part of the study. The instruments were piloted with two students from each year (1st, 2nd, 3rd, 4 th) with the purpose of checking the reliability and validity of the tools in addition to asking the opinion of an expert academician.

The survey included nine multiple-choice questions and inquiry to determine their genders and grades. The questions in the survey aimed at eliciting the general feelings and opinions of the participants related to the exam-based approach and task-based approach giving hints on summative and formative evaluation respectively.

The interview sessions were carried out in parallel with the survey. The interview consisted of five open-ended questions that were forwarded to the participants in a written way. The open-ended questions helped to collect qualitative data and crosscheck the opinions, feelings and beliefs of the participants in the survey. The interview questions were applied intentionally in a written way to allow more time, freedom, and comfort for the participants.

\section{Procedure}

The study was carried out in three stages. First, the data collection tools were piloted with students from the department, and the necessary corrections and/or modifications or alterations were applied. Second, the survey was applied, and third, the interview was done. All of these three stages were carried out during the spring semester of the 20172018 educational year.

\section{Data Collection}

The data collection tools, i.e. the survey and interview, were carried out individually with the available volunteers through Google Forms at various times. Both the survey and interview were provided to each participant in their L1 in order to prevent short answers. The survey took approximately two minutes and the interview took approximately four minutes to complete for each student. 


\section{Data Analysis}

Google Forms calculated each participant's responses for the survey automatically, and inferential statistics were revealed. The total percentages of the survey generated quantitative data. On the other hand, data collected from the interviews generated qualitative data. The interview data were subjected to content analysis. That is to say, responses of the students were reviewed in depth and similar contributions were gathered in the same groups under specific topic titles that were determined by the researchers in accordance with the answers of the participants.

\section{RESULTS AND DISCUSSION}

\section{Quantitative Results}

The results that were acquired from the survey question one of the present study are presented in Figure 1, which includes the percentages of the responses. While survey questions 6 and 7 are particularly related with Research Question 1, question 4 is specifically related with Research Question 2. All answers of the participants regarding the 9 survey questions were compiled and are presented in the following section.

\section{1-How do you feel when the mid-term and final exams approach?}
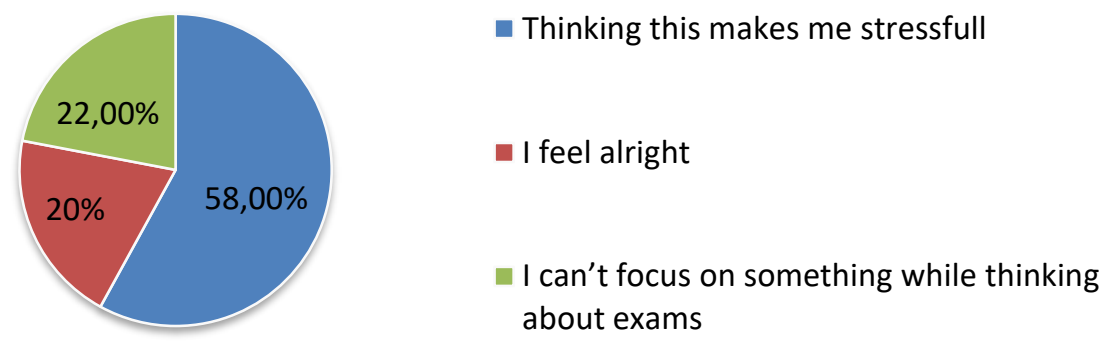

Figure 1. Responses given to survey question 1

The results show that for the first survey question (1- How do you feel when the midterm and final exams approach?), the 'Thinking about this makes me stressful' option was chosen by 29 students (58\%), the 'I feel alright' option was chosen by 10 students (20\%), and the 'I cannot focus on something while thinking about exams' option was chosen by 11 students (22\%). In sum, there was clear indication that students do not feel good about the exams. 


\section{2- How often do you study?}

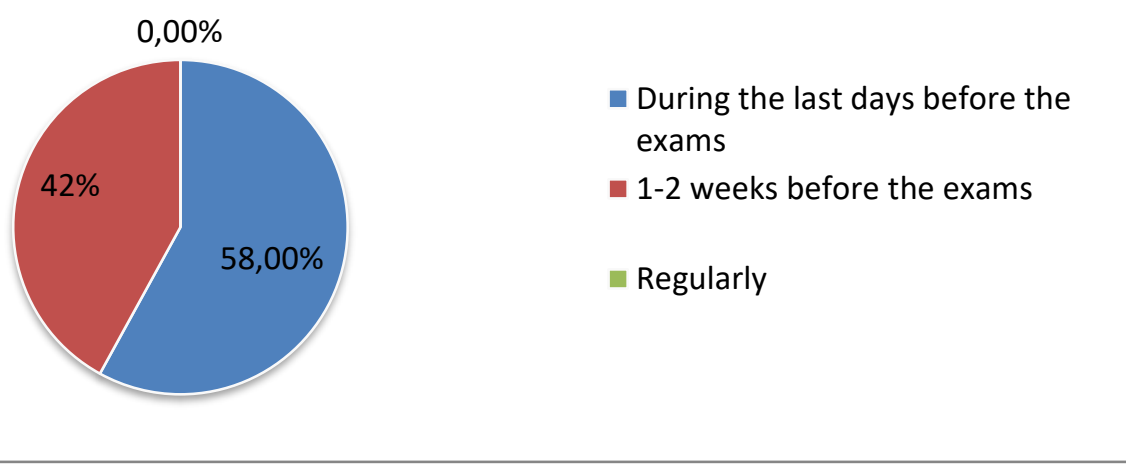

Figure 2. Responses given to survey question 2

For the second question of the survey (2- How often do you study?), it was revealed that 29 students (58\%) study during the last days before the exams, while 21 students (42\%) study for 1-2 weeks before the exams. The other option 'I study regularly' was not chosen by any of the participants. In sum, there was a clear indication that students study mostly for the exams rather than to learn and practice regularly.

3- Which one would you chose: In the exams;

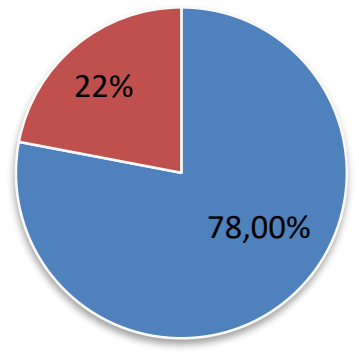

I don' think that I can express myself in the best way

I think that I can express myself completely

Figure 3. Responses given to survey question 3.

The results of the third survey question (3- Which one would you choose? In the exams) showed that 39 students (78\%) do not think that they can express themselves in the exams, whereas 11 students (22\%) think that they can express themselves in the best way in the exams. In sum, there was a clear indication that students do not feel very comfortable with the exams and/or believe that the exams do not allow them to show their real knowledge and skills. 


\section{4- Do you think that exams develop creative thinking skill?}

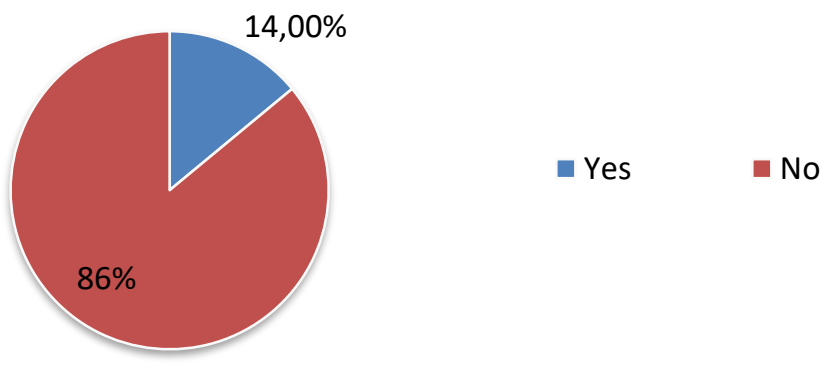

Figure 4. Responses given to survey question 4

The fourth survey question's (4- Do you think that exams develop creative thinking skills?) results demonstrated that 43 students (86\%) chose 'No', while 7 students (14\%) chose 'Yes', which is a clear indication that in the exams students mostly use their automated and memorised databases to complete the exam without critical or creative thinking. This might be due to the questions prepared and asked by the instructors and lecturers.

\section{5- Which assessment type would you prefer?}

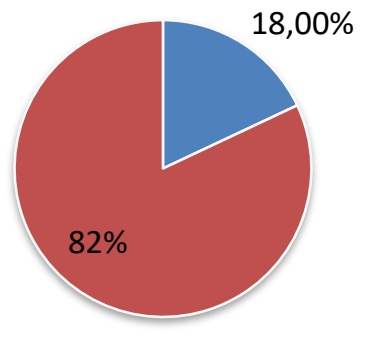

Mid-term and final exams

- Process evaluation (depending on the course and out of course duration)

Figure 5. Responses given to survey question 5

The results of the fifth survey question (5- Which assessment type would you prefer?) indicated that 41 students (82\%) would prefer process evaluation (depending on course and out-of-course duration (process-focused method) that includes debates, researches, weekly/monthly tasks, presentations etc.) whereas 9 students (18\%) would prefer midterm and final exams. This was an indication that students would be willing to distribute the stress and responsibility through the weeks rather than taking all of it at once or twice. However, there were still students who have become used to exams and tests, and preferred to have them. 


\section{6- Do you think that exams contribute to your professional life?}

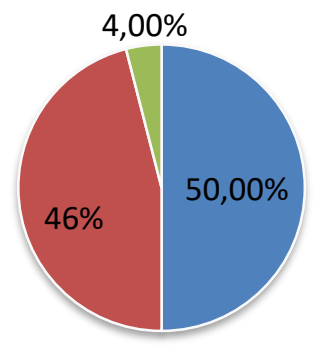

$\square$ No $\quad$ A little $\quad$ Yes

Figure 6. Responses given to survey question 6

According to the sixth question of the survey (6- Do you think that exams will contribute to your professional life?), it was found out that half of the students $(50 \%)(n=25)$ answered 'No', 23 students (46\%) answered 'A little' and 2 of the students (4\%) answered 'Yes'. There was a clear indication that exams do not help students much in becoming better professionals.

\section{7- What kind of effect do exams cause on your personal life?}

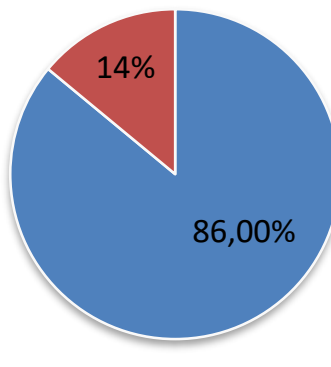

Negative $\quad$ Positive

Figure 7. Responses given to survey question 7

The results of the seventh survey question (7- What kind of effect do exams cause on your personal life?) indicated that 43 students (86\%) answered 'Negative', while 7 students (14\%) answered 'Positive'. Once again, there was a clear indication that exams affect the majority of the students negatively despite the fact that there might be some students who are very good at exams. Therefore, it might be a good idea to research how and why those students keep a good relationship with exams. 


\section{8- How would you feel if the assessments were based on tasks and out-of-course research?}

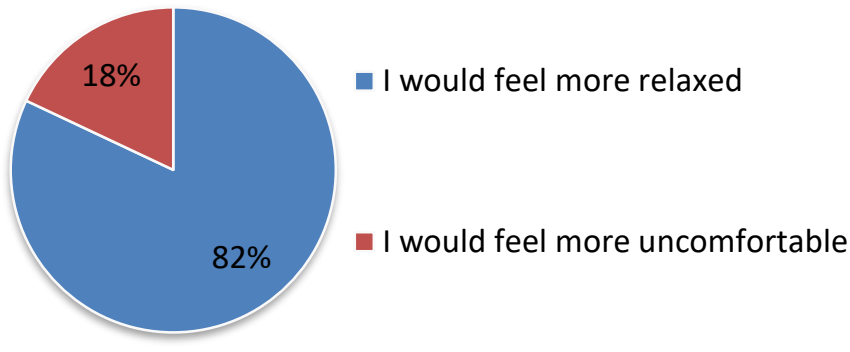

Figure 8. Responses given to survey question 8

The results of the eighth question (8- How would you feel if the assessments were based on tasks and out-of-course research (process-focused method, debates, researches, weekly/monthly tasks, presentations etc.)?) demonstrated that 41 students $(82 \%)$ answered 'I would feel more relaxed', while the rest of the participants $(n=9)(18 \%)$ answered 'I would feel more uncomfortable'. The majority of the participants, once again, preferred to do tasks and research out of the class as a duty for receiving their grade rather than being exposed to and assessed by one or two sittings of exams.

\section{9- Choose the best option for you;}

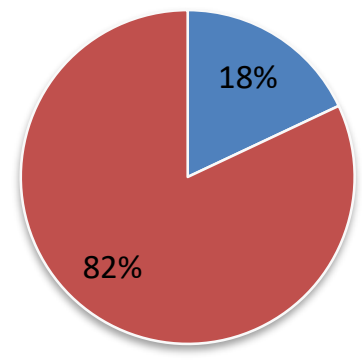

Even a long time after the exams I can still remember all the things that I have learned

- Even a short time after the exams I cannot remember all the things that I have learned

Figure 9. Responses given to survey question 9

According to the last survey question (9- Choose the best option for you.), it was revealed that the majority of the students $(n=41)(82 \%)$ answered 'Even a short time after the exams I cannot remember all the things that I have learned', while 9 students $(18 \%)$ answered 'Most of the time after the exams I can still remember the things that I have learned'. This indicates that for some reason students tend to forget the things that they knew during the exams. 
In sum, these findings suggest that students feel more comfortable with the processbased system and do not want to be restricted with just mid-term and final exams. Furthermore, it would be possible to add that the majority of the students think that exams do not contribute to their professional life but make them more stressful and also that even a short time after the exams they cannot remember the things they have learned, which suggests that the information learned or memorised with the purpose of passing the exams is temporary.

\section{Qualitative Results}

The interview results provided parallel findings with the survey results. All answers given by the participants regarding the five interview questions were compiled and are presented in the following section. It should be noted that interview question 4 and 5 are particularly concerned with Research Question 3. Content analysis generated the following information:

Interview Question 1. If you think/do not think that exams develop creative thinking, what might be the reason?

From the total of 50 interviewed participants, 29 students (58\%) stated that because exams are based on memorization and have close-ended questions, they do not think that exams develop creative thinking. 14 students (28\%) indicated that they do not think that exams develop creative thinking for the reason that exams have a stressful environment and that process and creative thinking cannot emerge and be enhanced easily in that kind of environment. On the other hand, 7 students (14\%) commented that exams develop creative thinking while trying to find a solution to how they can study more effectively to be successful in those kinds of exams.

Interview Question 2. Which lesson/lessons that you have taken so far do you think can contribute to your professional and personal life? (More than one course can be written.)

The students who indicated the Listening and Pronunciation course as an answer were 1st $(n=2)$ and 2 nd $(n=2)$ year students. English-Turkish/Turkish-English Translation was chosen by 3rd year students $(n=2)$. Finally, the Advanced Speaking course was written as a response by 4 th year students.

It has been investigated afterwards and determined that the lecturers/instructors of the abovementioned courses either used a task-based course delivery system that allowed learning by doing and practicing or formative evaluation, at least in one part of the course. It was meaningful that from among a total of approximately 40 courses in the curriculum, the names of only 12 of the courses have been mentioned by the students. This might suggest that most of the courses follow pure theoretical lecturing and/or an exam-based approach that do not create permanent effects and influences. The names of the courses are stated in the following together with the frequencies that their names were mentioned. 
Table 2.

The names of the most often mentioned courses by the students

\begin{tabular}{lc}
\hline Name of the Course & Frequency \\
\hline Approaches to ELT & 18 \\
Teaching English to Young Learners & 13 \\
Educational Philosophies & 8 \\
Educational Technologies and Materials Design & 7 \\
Teaching Practice & 7 \\
Scientific Research Methods & 6 \\
ELT Methodology & 6 \\
Listening and Pronunciation & 4 \\
Advanced Speaking & 3 \\
Oral Communication Skills & 2 \\
English-Turkish/Turkish-English Translation & 2 \\
Advanced Writing & 1 \\
\hline
\end{tabular}

Considering the responses of the 50 students who were interviewed, the course that contributes to their professional and personal life the most is the Approaches to ELT course, followed by Teaching English to Young Learners. The year of the students who wrote the Approaches to ELT course were as follows: 2nd year students $(n=10), 3$ rd year students $(n=4)$ and 4 th year students $(n=4)$. Because the number of the students who were 2 nd year was in the majority among all students, this might have been reason why the Approaches to ELT course was indicated more than the other courses. The Approaches to ELT course is a course of the second year in the curriculum, which is fresh in the memory for the second-year students, and a condition to easier evaluate the course and the process they have been through. Similarly, all of the 4th year students except one $(n=13)$ stated the Teaching English to Young Learners course, as this is a course of the fourth year in the curriculum. In third place there is the Educational Philosophies course, which was indicated 8 times. The students who stated the Educational Philosophies course were all 2nd year students. The Educational Technologies and Materials Design, and Teaching Practice courses come afterwards in fourth place. The participants that answered as Educational Technologies and Materials Design were all 2nd year students. The participants who answered as Teaching Practice were naturally 4 th year students as this course is installed in the last semester of the last year of the program. Scientific Research Methods and ELT Methodology were indicated 6 times each. The students that wrote Scientific Research Methods as an answer were 2nd 
year students $(n=4)$, a 3rd year student $(n=1)$ and a 4th year student $(n=1)$. The students who indicated ELT Methodology as an answer were 2nd year students $(n=4)$ and 3rd year students $(n=2)$. The students who wrote Advanced Writing $(n=1)$ and Oral Communication Skills $(n=2)$ were all 1st year students. Therefore, it was expected that all participants would mention only the names of the courses that they have taken.

Interview Question 3. Why do you think this/these lesson/lessons can contribute to your professional and personal life?

The results for this question were divided into 3 groups according to the answers given by students. The Approaches to ELT, ELT Methodology, and Teaching English to Young Learners, Educational Technologies and Materials Design, and Teaching Practice courses were chosen as an answer 51 times (66.23\%) because the students think that the courses provide them with efficient information for their professional life and enable them to practice their teaching skills. The Educational Philosophies and Scientific Research Methods courses were chosen as an answer by the students 14 times (18.18\%) because they think that the courses enable them to have different perspectives and enhance their creative and critical thinking. The Advanced Speaking, Advanced Writing, Listening and Pronunciation, Oral Communication Skills, and English-Turkish/TurkishEnglish Translation courses were chosen by the students 12 times (15.58\%) because they think that the courses are beneficial for their language development.

Additionally, students $(n=13)$ added that the efficiency of the courses that they chose can change according to the lecturers. Also, some of them $(n=11)$ indicated that because some courses do not have an exam, they enjoy them and learn more during the lessons. The information gathered hereby helps us to deduce that students value the following conditions:

a) Sufficient subject information accompanied by opportunities for practice

b) Inspiring content that brings different perspectives and triggers critical and creative thinking

c) Linguistic benefit

d) Good lecturers/instructors

e) Stress- and exam-free environment

Interview Question 4. Please write down one advantage and disadvantage of being evaluated with exams.

$76 \%$ of the students did not write any advantages, but only wrote disadvantages. Overall, as a disadvantage, they indicated that exams are stressful, essentially based and depending on memorization, and also added that the information that is learned with exam motivation is temporary. It has been stated that some unexpected things that are unrecoverable might happen during the exams and cannot be fixed, and therefore, exams cannot measure all of the skills that students possess, and appeal neither to all 
learning styles nor to all intelligence types. As an advantage, it was stated that exams are easy to pass and the required process is shorter, in addition to easier procedure for checking the results.

Interview Question 5. Please write down one advantage and disadvantage of being evaluated with the method that is based on tasks and out-of-class research (processfocused method) (debates, researches, weekly/monthly tasks, presentations etc.).

The advantages of the process-based methods were stated by students as in the following:

a) more flexible and comfortable

b) permanent because it is spread over time and allows intensive practice

c) no risk compared with something that may occur on the day of the exam

d) re-evaluation and correction are possible

e) student autonomy is developed more

f) improves responsibility and continuous track of education

On the other hand, the disadvantages of the process-based methods were indicated as in the following:

a) it needs more diligence, responsibility, and motivation

b) requires more effort and time

more tiring

\section{DISCUSSION AND CONCLUSION}

\section{Discussion}

It seems that the majority of the students find the task-based evaluation system more appropriate, effective, and useful in many ways compared to the exam-based evaluation system, although both of the assessment systems have certain disadvantages as discussed in the literature and revealed in the results. As it was indicated in Shi (2017), formative assessment appeals more to students' interests and enables them to learn more by practicing, which is not very possible in exams or tests. The present study also revealed that the students think that task-based education has more advantages than disadvantages. For the disadvantages, according to the students, it can be concluded that they do not want to take more responsibility and spend more time and effort in their out-of-school life. It was even mentioned that they would prefer to do everything in school with zero study out of school if possible. Furthermore, similar to Mohamadi et al. (2014), the present study ascertained that because of the stressful environment of the exam-based assessments, some unrecoverable things might happen on the day of the 
exams, and cannot be fixed afterwards, as well as these kinds of environments do not allow creative thinking to emerge easily, but seem to be oppressive. The findings and observations of the present study are in line with the conclusions drawn by Demir (2011) and the statements made related to test-oriented and exam-based education system. Moreover, the qualitative data collected from the participants matches the views of the Chinese students on the negative influences of exam-oriented education that were reported by Kirkpatrick and Zang (2011). These evidences suggest that the findings of the current research can be interpreted and regarded as universal since student psychology is more or less same everywhere in the world.

On the other hand, as Gan and Leung (2020) have illustrated, formative assessment can be properly implemented in task-based language teaching in ESL classrooms. Therefore, considering the results, the task-based assessment system seems not only more appropriate for students but also more beneficial. However, it should be stressed that task-based education and formative evaluation can yield useful outcomes only if the necessary responsibility is acquired by the students. It can be quite efficient for both the professional and personal lives of the students, and can also develop their creative thinking, which is a crucial element in education. Otherwise, without creativity, the whole process will revert to a period in which certain information is memorised, used in the exams, and then forgotten. The present study directly reflects the philosophical and pedagogical stance of what Norris (2016, p. 230) stated as in the following:

"In fact, major innovations in the general domain of language assessment over the past two decades have occurred in conjunction with the introduction of tasks into assessment design, largely in response to the need for tests that better represent examinees' abilities to use the language (Mislevy, Steinberg \& Almond, 2002), but also because tasks offer a meaningful space for language teachers, testers, learners, and others to examine, understand, and improve language learning endeavors (Van Gorp \& Deygers, 2013)."

The data collected in the present study and observations showed strong supportive evidence towards the discussions with regard to the advantages of task-based approach and formative evaluation in education and the shortcomings of exam-based approach and summative assessment.

\section{Conclusion}

Consequently, according to students' opinions on task-based and exam-based approaches, results suggested that the majority of the students are not satisfied with the exam-based approach for the reason that instead of improving their creative thinking and developing them personally and professionally, it encourages them just to be good at memorization. Thus, it seems that if the approach to education is revised and reconstructed in schools, students may gain the most possible benefit, and develop more in a way that makes their perspectives and knowledge more fruitful and promising, which will help and contribute more to their environment as well as themselves. This may be assured by employing task-based, project-based, problem-based, etc. education 
systems that will necessitate formative evaluation rather than summative assessment systems that mostly focus and rely on exams and tests.

\section{Limitations and Suggestions for Further Research}

The results of the present study were obtained from students of the ELT Department in Bursa Uludag University, so if further researches were carried out in other departments and universities, more reliable and generalizable results might be revealed. Furthermore, if the number of participants was increased and participants were selected equally from all grades, more precise results might be obtained.

\section{References}

Alderson, J. C. (2005). Diagnosing foreign language proficiency: The interface between learning and assessment. A\&C Black.

Alvarez, L., Ananda, S., Walqui, A., Sato, E., \& Rabinowitz, S. (2014). Focusing formative assessment on the needs of English language learners. San Francisco, CA: WestEd.

Antoniou, P., \& James, M. (2014). Exploring formative assessment in primary school classrooms: Developing a framework of actions and strategies. Educational Assessment, Evaluation and Accountability, 26(2), 153-176.

Baranovskaya, T., \& Shaforostova, V. (2017). Assessment and Evaluation Techniques. Journal of Language and Education, 3(2), 30-38.

Buren, A.V. (n.d.) Retrieved March 9, 2018 from http://thinkexist.com

Cheng, L., Rogers, T., \& Hu, H. (2004). ESL/EFL instructors' classroom assessment practices: Purposes, methods, and procedures. Language Testing, 21(3), 360-389.

Demir, S. (2011). An Overview of Peace Education in Turkey: Definitions, Difficulties, and Suggestions--A Qualitative Analysis. Educational Sciences: Theory and Practice, 11(4), 1739-1745.

Dixson, D. D., \& Worrell, F. C. (2016). Formative and summative assessment in the classroom. Theory into practice, 55(2), 153-159.

Erarslan, A. (2018). Strengths and weaknesses of primary school English language teaching programs in Turkey: Issues regarding program components. Eurasian Journal of Applied Linguistics, 4(2), 325-347.

Gan, Z., \& Leung, C. (2020). Illustrating formative assessment in task-based language teaching. ELT Journal, 74(1), 10-19.

Garrison, C., \& Ehringhaus, M. (2007). Formative and summative assessments in the classroom. Retrieved from: http://www.amle.org/Publications/WebExclusive/Assessment/tabid/1120/Default.aspx

Cantillon, P., Wood, D. F., \& Yardley, S. (Eds.). (2017). ABC of learning and teaching in medicine. John Wiley \& Sons.

Hadi, A. (2013). Perceptions of Task-Based Language Teaching: A Study of Iranian EFL Learners. English Language Teaching, 6(1), 103-111.

Hismanoğlu, S. (2012). İngilizce öğretmeni adaylarının İngilizce öğretmeni yetiştirme programı ile ilgili görüşleri. Eğitim ve Öğretim Araştırmaları Dergisi, 1(2), 330-341. 
Jensen, J. L., McDaniel, M. A., Woodard, S. M., \& Kummer, T. A. (2014). Teaching to the test... or testing to teach: Exams requiring higher order thinking skills encourage greater conceptual understanding. Educational Psychology Review, 26(2), 307-329.

Ketabi, S., \& Ketabi, S. (2014). Classroom and formative assessment in second/foreign language teaching and learning. Theory and Practice in Language Studies, 4(2), 435.

Kılıçkaya, F. (2016). Washback effects of a high-stakes exam on lower secondary school English teachers' practices in the classroom. Lublin Studies in Modern Languages and Literature, $40(1), 116$.

Kilimci, S. (2009). Teacher training in some EU countries and Turkey: How similar are they?. Procedia-Social and Behavioral Sciences, 1(1), 1975-1980.

Kirkpatrick, R., \& Zang, Y. (2011). The negative influences of exam-oriented education on Chinese high school students: Backwash from classroom to child. Language testing in Asia, 1(3), 36.

Lau, A. M. S. (2016). 'Formative good, summative bad?'-A review of the dichotomy in assessment literature. Journal of Further and Higher Education, 40(4), 509-525.

López-Pastor, V., \& Sicilia-Camacho, A. (2017). Formative and shared assessment in higher education. Lessons learned and challenges for the future. Assessment \& Evaluation in Higher Education, 42(1), 77-97.

Lovett, M. C. (2013). Make exams worth more than the grade: Using exam wrappers to promote metacognition. In M. Kaplan, N. Silver, D. Lavaque-Manty, and D. Meizlish (Eds.). Using reflection and metacognition to improve student learning: Across the disciplines, across the academy (pp. 18-52). Stylus Publishing, LLC..

Mackatiani, C. I. (2017). Influence of Examinations Oriented Approaches on Quality Education in Primary Schools in Kenya. Journal of Education and Practice, 8(14), 51-58.

McDowell, L. (1995). The impact of innovative assessment on student learning. Innovations in Education and Training International, 32(4), 302-313.

Miller, R. L., King, J. A., Mark, M. M., \& Caracelli, V. (2016). The oral history of evaluation: The professional development of Robert Stake. American Journal of Evaluation, 37(2), 287-294.

Mohamadi, M., Alishahi, Z., \& Soleimani, N. (2014). A study on test anxiety and its relationship to test score and self-actualization of academic EFL students in Iran. Procedia-Social and Behavioral Sciences, 98, 1156-1164.

Norris, J. M. (2016). Current uses for task-based language assessment. Annual Review of Applied Linguistics, 36, 230-244.

Öztürk, G., \& Aydın, B. (2019). English Language Teacher Education in Turkey: Why Do We Fail and What Policy Reforms Are Needed?. Anadolu Üniversitesi Eğitim Bilimleri Enstitüsü Dergisi, 9(1), 181-213.

Prabu, P. S. (2015). A study on academic stress among higher secondary students. International Journal of Humanities and Social Science Invention, 4(10), 63-68.

Rillero, P., \& Padgett, H. (2012). Supporting Deep Conceptual Learning: Technology Can Help Educators Train Students' Focus Away from Rote Memorization toward Deep Conceptual Learning by Building on Prior Knowledge and Making Connections between Concepts. THE Journal (Technological Horizons In Education), 39(9), 37. 
Santamaría Lancho, M., Hernández, M., Sánchez-Elvira Paniagua, Á., Luzón Encabo, J. M., \& de Jorge-Botana, G. (2018). Using Semantic Technologies for Formative Assessment and Scoring in Large Courses and MOOCs. Journal of Interactive Media in Education, 1(12), 1-10.

Shi, H. (2017) Examining the Effectiveness of Formative Assessment in English Vocabulary Learning of Senior High School Students in China. Asian EFL Journal, 101, 61-82.

Stake, P. (Scriven, 1991:169) "What is Formative Assessment?" Retrieved March 18, 2018 from: http://teachingthroughthearts.blogspot.com/2011/07/formative-assessment-when-cooktastes.html

Taras, M. (2005). Assessment-summative and formative-some theoretical reflections. British journal of educational studies, 53(4), 466-478.

Taras, M. (2008). Summative and formative assessment: Perceptions and realities. Active learning in higher education, 9(2), 172-192.

Teodorczuk, A., Fraser, J., \& Rogers, G. D. (2018). Open book exams: A potential solution to the "full curriculum"?. Medical teacher, 40(5), 529-530.

Uztosun, M. S. (2013). An interpretive study into elementary school English teachers' beliefs and practices in Turkey. Turkish Online Journal of Qualitative Inquiry, 4(1), 20-33.

Uzun, L. (2012). What is your educational philosophy? Modern and postmodern approaches to foreign language education. Studies in Second Language Learning and Teaching, 2(3), 333348.

Uzun, L. (2014). Raising Awareness of Educational Philosophy: Learning and Education in Posthumanistic Philosophy. Journal of Theory and Practice in Education, 10(3), 613-626.

Uzun, L. (2016). Evaluation of the latest English language teacher training programme in Turkey: Teacher trainees' perspective. Cogent Education, 3(1), 1147115.

Yavuz, A., \& Zehir Topkaya, E. (2013). Teacher Educators' Evaluation of the English Language Teaching Program: A Turkish Case. Novitas-royal (research on youth and language), 7(1), 64-83.

Yu, L., \& Suen, H. K. (2005). Historical and contemporary exam-driven education fever in China. KEDI Journal of Educational Policy, 2(1), 17-33. 


\section{Appendix A}

Task-Based versus Exam-Based Approaches

Gender:

Year in school:

Choose the best options for you

How do you feel when the mid-term and final exams approach?

Thinking about this makes me stressful

I feel better

I cannot focus on something while thinking about exams

$\square$ I do not think much about exams

How often do you study?

Regularly

1-2 weeks before the exams

During the last few days before the exams

Which one would you choose? In the exams;

I think that I can express myself in the best way

I do not think that I can express myself completely

Do you think that exams develop creative thinking skills?

$\square \quad$ Yes

$\square$ No

Which assessment type would you prefer?

Mid-term and final exams

Process evaluation (based on tasks and out-of-course research (process-focused method) that includes debates, researches, weekly/monthly tasks, presentations etc.)

Do you think that exams will contribute to your professional life?

Yes

A little

$\square$ No

What kind of effect do exams cause on your life?

Positive

Negative

How would you feel if the assessments were based on tasks and out-of-course research (processfocused method) (debates, researches, weekly/monthly tasks, presentations etc.)?

I would feel more relaxed

I would feel more uncomfortable

Choose the best option for you;

Even a long time after the exams I can still remember all the things that I have learned for the exams

Even a short time after the exams I cannot remember all the things that I have learned for the exams 


\section{Appendix B}

Please express your ideas according to the questions below.

1. If you think/do not think that exams develop creative thinking, what might be the reason?

2. Which lesson/lessons that you have taken so far do you think can contribute to your professional and personal life? (More than one course can be written.)

3. Why do you think this/these lesson/lessons can contribute to your professional and personal life?

4. Please write down one advantage and disadvantage of being evaluated with exams.

5. Please write down one advantage and disadvantage of being evaluated with the method that is based on tasks and out-of-class research (process-focused method) (debates, researches, weekly/monthly tasks, presentations etc.). 
In the writing process of the study titled "Student Opinions on Task-Based Approach as Formative Evaluation versus Exam-Based Approach as Summative Evaluation in Education", the rules of scientific, ethical and citation were followed; it was undertaken by the authors of this study that no falsification was made on the collected data. "Sakarya University Journal of Education Journal and Editor" had no responsibility for all ethical violations to be encountered, and all responsibility belongs to the authors and that the study was not submitted for evaluation to any other academic publishing environment. 